\title{
DIFICULDADES E DESAFIOS NA APLICAÇÃO DE METODOLOGIAS ATIVAS NO ENSINO DE TURISMO: UM ESTUDO EM INSTITUIÇÃO DE ENSINO SUPERIOR
}

\author{
DIFFICULTIES AND CHALLENGES IN THE IMPLEMENTATION OF ACTIVE METHODOLOGIES IN \\ TOURISM EDUCATION: A STUDY IN A HIGHER EDUCATION INSTITUTION
}

\section{DIFICULTADES Y DESAFÍOS EN LA APLICACIÓN DE METODOLOGÍAS ACTIVAS EN LA ENSEÑANZA DEL TURISMO: UN ESTUDIO EN INSTITUCIÓN DE EDUCACIÓN SUPERIOR}

\section{Eugênia Patrícia de Almeida Seixas}

Professora da Estácio - Faculdade de Natal Mestra em Turismo pela Universidade Federal do Rio Grande do Norte seixaspatricia@yahoo.com.br

Maria Valéria Pereira de Araújo Professora do Programa de Pós-Graduação em Turismo da Universidade Federal do Rio Grande do Norte Doutora em Administração pela Universidade Federal da Paraíba valeriaaraujoufrn@gmail.com

Max Leandro de Araújo Brito Professor da Faculdade Natalense de Ensino e Cultura Doutor em Energia pela Universidade Federal do ABC maxlabrito@yahoo.com.br

Géssica Fabiely Fonseca Professora do Centro de Educação da Universidade Federal do Rio Grande do Norte Doutora em Educação pela Universidade Federal do Rio Grande do Norte gessicafabiely@hotmail.com

Data de Submissão: 14/07/2016 Data de Aprovação: 01/08/2017

RESUMO: A discussão sobre o ensino de turismo em nível de graduação ainda é emergente no Brasil, principalmente quando enfoca a aplicação de metodologias ativas. Uma metodologia ativa de ensino aprendizagem compreende uma concepção educacional que estimula a aprendizagem em processos de desafios construtivos, que se torna como uma aprender-ação, pois, quanto mais se aprende o que está mais próximo da vida, melhor se torna e isto acaba sendo o ponto de partida para o avanço em processos, desenvolvimentos, inovação e tecnologia, assim criando uma reelaboração de novas práticas. Desse modo, o presente estudo tem por objetivo discutir sobre as dificuldades e os desafios da aplicação de metodologias ativas no ensino de turismo em instituição de ensino superior. A metodologia utilizada é qualitativa, compreendendo um estudo de caso de natureza exploratória junto a docentes do curso de graduação em turismo da Universidade Federal do Rio Grande do Norte (UFRN). Os resultados do estudo revelam que existem dificuldade de implementar metodologias ativas no dia a dia. Por fim, o estudo conclui que as dificuldades e os desafios que mais se destacaram na percepção docente dizem respeito a motivar o aluno e a fazer com que ele perceba a contribuição proporcionada pela teoria apresentada em sala de aula na formação profissional.

PALAVRAS-CHAVE: Turismo. Formação superior. Metodologia ativa. Aprendizagem.

ABSTRACT: The discussion about tourism education at undergraduate level is still in its infancy in Brazil, especially when it comes to the application of active methodologies. An active teaching-learning methodology is an educational concept that stimulates learning in processes of constructive challenges, where it becomes a form of action-learning, because the more we learn what is closer to life, the better we become, and this becomes the starting point for the advancement of processes, developments, innovation and technology, thereby creating a re-elaboration of new practices. This study 
ISSN: 1983-7151

therefore discusses the difficulties and challenges of the application of active methodologies in the teaching of tourism in a higher education institution. The methodology used is qualitative, comprising an exploratory case study with teachers of the undergraduate course in tourism of the Universidade Federal do Rio Grande do Norte (UFRN). The study shows that there are difficulties in implementing active methodologies in the day to day routine. Finally, the study concludes that the difficulties and challenges that most stood out, in the teacher's perceptions, were motivating the student and making him/her perceive the contribution provided by the theory presented in the classroom in vocational training.

KEYWORDS: Tourism. Higher education. Active methodology. Learning.

RESUMEN: La discusión sobre la enseñanza de turismo a nivel de graduación sigue siendo emergente en Brasil, principalmente cuando se enfoca la aplicación de metodologías activas. Una metodología activa de enseñanza aprendizaje comprende una concepción educativa que estimula el aprendizaje en procesos de desafíos constructivos, donde se convierte en un aprendizaje-acción, pues cuanto más aprendemos lo que está más cerca de la vida, mejor queda, y esto termina siendo el punto de partida para el avance en procesos, desarrollos, innovación y tecnología, creando así una reelaboración de nuevas prácticas. De este modo, el presente estudio tiene por objetivo discutir sobre las dificultades y desafíos de la aplicación de metodologías activas en la enseñanza de turismo en institución de enseñanza superior. La metodología utilizada es cualitativa, y comprende un estudio de caso de naturaleza exploratoria con docentes del curso de graduación en turismo de la Universidad Federal de Rio Grande do Norte (UFRN). Los resultados del estudio revelan que existen dificultades para implementar metodologías activas en el día a día. Por último, el estudio concluye que las dificultades y desafíos que más se destacaron en la percepción docente se refieren a motivar al alumno y a hacerle percibir la contribución proporcionada por la teoría presentada en el aula en la formación profesional.

PALABRAS CLAVE: Turismo. Educación superior. Metodología activa. Aprendizaje.

INTRODUÇÃO

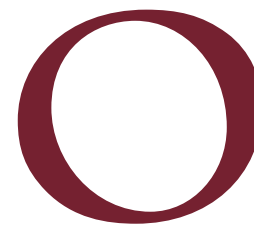

ensino tradicional de turismo ainda é amplamente divulgado e utilizado até os dias atuais, tendo uma forte influência do mecanicismo de inspiração cartesiana, newtoniana, fragmentado e reducionista. E essa fragmentação do saber manifestou-se no fortalecimento das subdivisões e, nesse sentido, o processo ensino-aprendizagem tem se restringido muitas vezes à reprodução do conhecimento, cujo docente assume um papel de transmissor de conteúdos e ao discente cabe a retenção e a repetição em uma atitude passiva e receptiva, tornando-se mero expectador, sem a necessária crítica e reflexão (Capra, 2006).

As teorias educativas tradicionais concebem o fenômeno educativo como uma relação de causa-efeito, linear, preconcebido, ordenado e estabilizado em uma aula, na qual o professor ensina e os alunos aprendem, utilizam-se materiais auxiliares para o ensino e se desenvolvem algumas dinâmicas que a própria teoria diz como controlar (Colom, 2006).

Com relação à adoção das aplicações metodológicas por parte do docente, torna-se relevante salientar que existem perfis diferentes de docentes em sala de aula e que é preciso que haja respeito ao modo como ele enxerga 
o seu saber e como o expressa no ato de ensinar, porém há uma percepção que quando o docente opta por uma determinada forma de agir é porque ele estabeleceu e direcionou suas ações no desenvolvimento de um propósito (Fonseca e Magalhães, 2016). Assim, percebe-se que não existe uma única estrutura que categorize todos os perfis docentes, embora perceba que os autores têm que optar por micro decisões, para que possa direcionar suas ações em cada momento. Existem professores que associam a prática do ato pedagógico a algo pesado, desestimulante e desgastante. Essa percepção deve estar vinculada ao fato de encontrar em sala de aula, muitas vezes, alunos que participam efetivamente do processo pedagógico e outros que apenas assistem a um processo educacional, vendo-o passar, sem nenhum tipo de relacionamento com o aprendizado (Cunha, 2012).

Cabe salientar que na graduação em Turismo no Brasil existe uma dificuldade em relação à formação do docente, uma vez que uma grande quantidade de professores não recebeu formação pedagógica durante o Ensino Superior. A maior aproximação com a docência ocorre nos programas de pós-graduação stricto sensu que possuem maior ênfase em atividade de pesquisa e de produção de conhecimento em detrimento da formação pedagógica (Corrêa e Ribeiro, 2013, Masetto e Gaeta, 2015).

Tendo em vista o contexto apresentado, o presente estudo tem por objetivo discutir sobre as dificuldades e os desafios da aplicação de metodologias ativas no ensino de turismo em instituição de Ensino Superior. Mais especificamente, procura entender o desafio de motivar na atuação docente no turismo, revelar a importância do conteúdo trabalhado na perspectiva dos docentes, apontar as dificuldades na aplicação das metodologias de ensino, apresentar as dificuldades e os desafios na atuação profissional como docente, abordar o relacionamento entre os diferentes departamentos.

O presente estudo se justifica pela necessidade de aprofundamento sobre as impressões de professores que atuam em um curso de turismo sobre as metodologias adotadas, tendo em vista as particularidades e a complexidade da área. O trabalho torna-se relevante devido à carência de estudos e pesquisas voltadas para o estudo das metodologias ativas no ensino do turismo. Para tanto, em um primeiro momento é realizada uma apresentação de práticas, 
dificuldades e desafios na aplicação das metodologias, seguida da elucidação da metodologia utilizada na pesquisa, por fim apresentam-se os resultados e a conclusão.

\section{PRÁTICAS, DIFICULDADES E DESAFIOS NA APLICAÇÃO DAS METODOLOGIAS}

Um dos elementos básicos de discussão da ação docente refere-se ao ensinar, ao aprender e ao apreender. Ações essas que muitas vezes são executadas de forma disjunta. E isso decorre da ideia de que ensinar é apresentar ou explicar o conteúdo numa exposição. A compreensão do que seja ensinar é um elemento fundamental nesse processo. Todavia é sabido que o significado das palavras varia em razão das práticas sociais dos povos, revelando as diferentes concepções que decorrem dessa prática (Anastasiou e Alves, 2012).

Com relação à postura dos docentes em sala de aula, autores como Freire (2014), Perrenoud (1993) e Bourdieu (1972) destacam a ação docente e a existência de perfis diferentes de docentes em sala de aula. Para Freire (2014), os docentes devem possuir alguns saberes no que se refere ao ato de ensinar. A rigorosidade metódica; pesquisa; respeito aos saberes do educando; exigese criticidade; estética e ética; corporificação das palavras pelo exemplo; risco e aceitação do novo, além de rejeição a qualquer forma de descriminação; reflexão crítica sobre a prática e o reconhecimento e a assunção cultural. Já Perrenoud (1993) comenta que a ação docente, cada vez mais, precisa dar conta de situações planejadas, conhecidas e esperadas como também situações inusitadas, o que provoca e permite o docente desenvolver uma infinidade de práticas adaptadas às situações. Por fim, Bourdieu (1972) valoriza a questão do perfil docente atrelado às experiências passadas, que em cada momento se torna possível a concretização de tarefas infinitamente diferenciadas, graças às transferências analógicas que possibilitam resolver problemas da mesma natureza.

E é nesse cenário que uma parte dos docentes atua no ensino brasileiro. $\mathrm{O}$ docente, sua formação, sua prática em serviço, como é que ele se define nesse contexto. Será que ele percebe sua própria trajetória (Fonseca e Magalhães, 2016)? O professor com relação à escola é, ao mesmo tempo, determinante 
e determinado. Há uma variedade de fatores que determinam seu perfil e suas manifestações. A escola, analisada em diferentes momentos históricos, certamente mostrará realidades também diferenciadas. Esse jogo de relações entre a escola e a sociedade precisa ser cada vez mais desvendado para que se possa compreender e interferir na prática pedagógica. Uma visão simplista diria que a função do professor é ensinar e poderia reduzir este ato a uma perspectiva mecânica, descontextualizada. Entretanto, sabe-se que o professor não ensina no vazio. $O$ ensino é sempre situado, com alunos reais em situações definidas. E nessa definição interferem os fatores internos da escola, assim como as questões sociais mais amplas que identificam uma cultura e um momento histórico político (Cunha, 2012). O jogo de relações entre a escola e a sociedade está presente no ensino de Turismo em todos os continentes, inclusive no europeu e africano, fazendo com que seja dispensada uma grande quantidade de trabalho e perseverança para fomentar o aprendizado (Bhandari, 2017).

A leitura dos principais pensadores brasileiros leva a perceber que há o reconhecimento comum de alguns aspectos fundamentais na formação de professores, em que a proposta de formação depende da concepção que se tem de educação e de seu papel na sociedade desejada (Fonseca e Magalhães, 2016). Quase todas as propostas atuais contemplam o saber específico, o saber pedagógico e o saber político social como partes integrantes da formação dos professores, como ressalta Cunha (2012). Os cursos de mestrado e doutorado voltados para o turismo ainda são recentes no Brasil, mas aos poucos promovem um aumento de visão teórica, técnica e profissional no preparo de profissionais para atuarem na docência do turismo (Lara, 2010). A busca por formação em nível de mestrado e doutorado em turismo no Brasil ocorreu principalmente por influência da legislação educacional a partir da LDB de 1996 que cria obrigações de titulação para a docência no ensino superior (Silveira, Medaglia e Gândara, 2012).

A formação de profissionais para o ensino no Brasil envolve diversas abordagens, dentre elas estão o Saber Específico, o Saber Pedagógico, e o Saber Político-Social. Segundo Fiorentini e Melo (1998), o Saber Específico alcança seu auge na década de 1960 e tem como característica principal a valorização quase exclusiva do conhecimento que o professor tinha sobre a sua disciplina. Na década de 1970, começa a se destacar o Saber Pedagógico, 
com a valorização dos aspectos didáticos metodológicos e sua relação com as tecnologias de ensino, passando assim para um segundo plano o domínio do conteúdo. Na década seguinte, o discurso educacional é dominado pelo Saber Político-Social na prática pedagógica, quando as pesquisas sobre o ensino e a formação do professor passaram a priorizar o estudo dos aspectos políticos e pedagógicos amplos.

Levar em conta essas premissas é também refazer as concepções sobre o conhecimento e sobre a ação de ensinar e aprender este conhecimento. A concepção de ensino e as práticas realizadas pelo professor certamente terão de ser diferenciadas conforme os objetivos se direcionem à internalização ou à conscientização. Isto significa ter uma concepção nova da relação existente entre o sujeito socialmente situado e o conhecimento. Significa entender que aprender não é estar em atitude contemplativa ou absorvente, frente aos dados culturais da sociedade, e sim estar ativamente envolvido na interpretação e na produção destes dados (Cunha, 2012).

A educação do professor nesse sentido deverá passar por uma nova concepção do processo ensino aprendizagem, derivará da recolocação do conhecimento na perspectiva histórico-social. É necessário caminhar por um ensino que favoreça a produção de conhecimento. Considera-se, assim, que este, em sua trajetória, constrói e reconstrói seus conhecimentos conforme a necessidade de sua utilização, de suas experiências e seus percursos formativos e profissionais (Nunes, 2001). Cabe ressaltar que os percursos formativos e profissionais dos professores de turismo no Brasil vêm evoluindo desde o século passado, com melhoria no nível de formação e titulação (Sogayar e Rejowski, 2011).

Quando se fala de metodologia, faz parte do senso comum e ratificado pelos órgãos institucionais que o professor possui um saber que lhe é próprio, cujo saber possui duas grandes direções: o domínio do conteúdo do ensino e o domínio das ciências de educação que lhe permitirão compreender e realizar o processo pedagógico (Cunha, 2012). Contudo, é importante ressaltar que no ensino de turismo pode ser relevante a noção de experiências do mercado, proporcionando aos alunos uma compreensão mais clara da realidade das empresas e dos problemas que enfrentam, e oferecendo o fomento de habilidades de comunicação, liderança, resolução de problemas, criatividade (Daniel, Costa, Pita e Costa, 2017). 
E diante do que foi dito, a prática docente segue algumas características que podem ser utilizadas independentes da metodologia de ensino adotada, porém é importante se ter consciência de quais metodologias estão sendo utilizadas ou desenvolvidas, para que haja um melhor aproveitamento da prática docente, mesmo havendo dificuldades e desafios no processo, o que acaba interferindo na nova forma de organizar o processo de ensino. Para o discente, altera a forma memorativa e a passividade do assistir a aulas e passa para o desafio de realizar operações mentais. Porém, essa ação do estudante só se efetivará a partir do direcionamento dado pelos professores ao processo, com a escolha e a efetivação de diferentes estratégias, constituindo-se assim como responsabilidade coletiva (Anastasiou e Alves, 2012).

Compreende-se que vários são os determinantes que interferem na alteração do fazer docente e das escolhas e ações diferenciadas no processo de aprendizagem (Fonseca e Magalhães, 2016). Nenhuma forma de conhecimento é, em si, racional, portanto dialoga com outras formas de conhecimento. $\mathrm{Na}$ visão de docentes universitários, o conhecimento a ser construído na sala de aula inclui a absorção de sinais adquiridos cotidianamente e são elementos já existentes na base cognitiva. É o resultado da investigação científica e de um processo de interação com a realidade observada e vivenciada (Anastasiou e Alves, 2012).

É nesse contexto que se constrói o trabalho docente e que o professor se vê frente a frente com a necessidade e o desafio de organizá-lo e operacionalizálo, como ressaltam as autoras. O professor deve se tornar um estrategista quando tem pela frente o estudar, selecionar, organizar e propor as melhores ferramentas que facilitem o estudante se apropriar do conhecimento.

METODOLOGIA

O presente trabalho compreende um estudo de caso qualitativo de natureza exploratória (Ponte, 2006) junto aos docentes da Universidade Federal do Rio Grande do Norte (UFRN). O estudo de caso trata-se de uma abordagem metodológica de investigação especialmente adequada quando se procura 
compreender, explorar ou descrever acontecimentos e contextos complexos, nos quais estão simultaneamente envolvidos diversos fatores.

Ao longo de dezenove anos, o Curso de Turismo da UFRN teve atualizado o seu Projeto Político Pedagógico três vezes, nos anos de 1999, 2004 e 2008 e tendo mais uma revisão prevista para o ano de 2015. E em cada atualização se buscou fomentar uma permanente crítica sobre seus conteúdos e métodos. $\mathrm{E}$ em cada revisão foram abordadas características específicas sobre o curso, que precisava de ajustes para atender uma demanda e manter-se em sintonia com as novas exigências.

No ano de 1999 o objetivo do projeto pedagógico era apresentar o Curso de Turismo da UFRN com vistas a um acompanhamento didático por parte da Coordenação e do Colegiado do Curso. Essa apresentação foi feita em três partes: a primeira foi composta pela introdução, pela missão da instituição, pelos objetivos do curso, pela caracterização da formação oferecida e pelo perfil e habilidades necessárias a esse profissional. A segunda parte apresenta as atividades de Ensino - Estrutura Curricular, Ementários de Disciplinas, Estágio Supervisionado, as atividades de pesquisa e de extensão e o número de bolsas de pesquisa e extensão existente a serem pleiteadas. A terceira mostra o processo de avaliação curricular prevista no projeto curricular.

No ato da apresentação do Projeto Pedagógico, o Curso de Turismo tinha como Objetivo Geral formar o bacharel em turismo com ampla capacidade para planejar e organizar o turismo nos diversos segmentos do setor, quer seja o setor público ou privado, enfatizando a hotelaria e a animação.

O segundo Projeto Pedagógico ocorreu no ano de 2004 e o intuito foi ratificar o projeto de 1999, não contendo nesse projeto modificações relevantes.

O terceiro projeto pedagógico e que ainda está em vigor no Curso de Turismo da UFRN ocorreu em 2008 e surgiu como resposta às exigências de mudanças indicadas pelo contexto no qual estão inseridos os Cursos de Turismo no País, da necessidade de mudança e manter-se em sintonia com as novas exigências. Tendo, agora, o projeto pedagógico para o curso de turismo um objetivo mais amplo e generalista e enfatizando o perfil do profissional para possibilitar 
uma formação consistente, fundamentada em conceitos sólidos das áreas de conhecimento, no aprofundamento de estudos e na flexibilização de novos elementos contextuais. O currículo do Curso de Turismo busca proporcionar uma formação mais direcionada para a realidade atual. A proposta está planejada e articulada para formar profissionais com as seguintes competências e habilidades:

O Curso de Turismo da UFRN foi criado em 1996 e iniciado em 1997. Ganhou maior impulso com a criação do Departamento de Turismo (DETUR) em 21 de maio de 2010, com a aprovação da Resolução n 005/2010-CONSUNI. O DETUR foi criado depois que o Curso de Turismo se desmembrou do Departamento de Ciências Administrativas, a partir da Portaria n²9/09-DEPAD. Em 09 de junho de 2010, foi publicada no Boletim de Serviço $n^{\circ} 105$ a oficialização do DETUR (Costa, 2013).

O universo da pesquisa abrange docentes que ministram aulas na graduação do Curso de Turismo na Universidade Federal do Rio Grande do Norte, a escolha desses sujeitos da pesquisa justifica-se pelo nível de conhecimento dos professores em relação à questão de pesquisa. Para a seleção dos sujeitos da pesquisa, foi solicitada junto à secretaria do curso de graduação de Turismo uma relação de docentes que estavam atuando no segundo semestre de 2014.

Dos 33 (trinta e três) docentes que atuaram no curso em 2014, 29 (vinte e nove) participaram do processo de pesquisa, portanto foi escolhida uma amostra por conveniência. Dos quatro docentes que não participaram da pesquisa, 01 (um) colabora diretamente com o desenvolvimento dessa pesquisa, sendo assim, excluído da coleta de dados, enquanto que os outros 03 (três) profissionais a pesquisadora não conseguiu contato em virtude da dificuldade de conciliar as agendas. Para a análise dos dados, os professores foram divididos de P01 até P29 como forma de resguardar a identidade. Como o Curso de Turismo é multidisciplinar, parte dos docentes entrevistados são provenientes de outros cursos, como: o de Geografia, História, Administração, Educação Física, Economia, Contabilidade, Línguas e Literatura Estrangeiras Modernas, Antropologia, Psicologia, além do Curso de Turismo. 
A coleta de dados iniciou na primeira quinzena de outubro de 2014. A coleta foi realizada por meio da aplicação de um roteiro de entrevista semiestruturado. Como destaca Duarte (2002), o roteiro de entrevista semiestruturado é utilizado em pesquisas de cunho qualitativo para promover uma conversação continuada entre o sujeito e o pesquisador.

O roteiro de entrevista semiestruturado do presente estudo foi composto por quatro questões que buscaram: identificar dados referentes às metodologias de ensino utilizadas em sala de aula; quais metodologias seriam mais apropriadas para o Curso de Turismo; quais as principais dificuldades na utilização dessas metodologias; como também quais as contribuições que essas metodologias podem ter para o desenvolvimento de competências do turismólogo.

Os dados foram tratados por meio de abordagem qualitativa que supõe um corte temporal-espacial. E esse corte definiu o campo e a dimensão em que o trabalho foi desenvolvido, ou seja, o território mapeado. Considerando o objetivo desta pesquisa e diante desse contexto, adotou-se a estratégia de análise por meio da construção de quadros de categorização. O objetivo dessa formulação é oferecer um breve panorama descritivo da história e do caso, visando descobrir padrões nos dados, assim como as condições sob as quais estes são aplicados (Strauss e Corbin, 1990).

\section{RESULTADOS}

Essa parte do artigo apresenta a análise e a discussão dos dados coletados nas entrevistas com os docentes do Curso de Turismo da UFRN. Ressalta-se que praticamente em todas as respostas dos docentes, mesmo nas questões que não tinham o intuito de analisar os problemas relacionados às escolhas pedagógicas, sempre foram ressaltados os desafios e as dificuldades.

Inicialmente, para entender um pouco mais as metodologias adotadas pelos docentes, procurou-se entender a percepção deles em relação a metodologias adotadas na sua disciplina. Pela análise dos discursos dos sujeitos, evidenciouse que a metodologia que mais se destaca junto aos docentes que atuam no Curso de Turismo da instituição compreende o pluralismo metodológico, sendo seguido pelas metodologias ativas e tradicionais. 
O pluralismo metodológico destacado pelos docentes foi registrado na fala de um sujeito, como também foi comentado no momento que outros docentes destacaram a utilização da combinação de metodologias adotadas na sua unidade curricular, tanto metodologias ativas como tradicionais.

"Utilizo o pluralismo metodológico, onde cada método revela diferentes aspectos da realidade social".

"Utilizo variadas técnicas de ensino, aulas expositivas, dinâmicas de grupo, leitura em sala de aula, apresentação de seminários, visitas técnicas".

"As metodologias usadas em minhas disciplinas elas vão desde aulas expositivas e dialogadas, até passando pela dramatização, pela resolução de problemas, pelo debate, pela leitura e interpretação de textos, por estudos dirigidos, mais principalmente pelo diálogo com o aluno".

As falas dos docentes apontaram, ainda, várias razões e motivos que influenciaram na escolha do pluralismo metodológico, alguns relataram: o conteúdo da disciplina e/ou o perfil da turma, conforme pode ser identificado nas falas dos sujeitos:

"Em função do perfil da turma e do aluno é estabelecida a metodologia mais adequada para ser utilizada".

"Eu ministro disciplinas diferentes, então elas precisam de metodologias diferentes e adequadas".

"Em relação às metodologias, eu tento adotar o máximo possível, dentro das minhas capacidades e do andamento da turma".

As falas dos sujeitos demonstram a possibilidade de utilizar uma gama metodológica e que o enfoque escolhido para ser trabalhado em sala pode gerar reflexos no processo ensino aprendizagem, já que os docentes levam em consideração aspectos que vão muito além do conteúdo a ser ministrado em sala.

Percebe-se ainda que a maior parte dos docentes pesquisados sabem que a escolha metodológica é deles, entendendo ainda que a definição das 
metodologias escolhidas para determinados componentes curriculares é contemplada a partir de análises dos aspectos: econômicos, sociais, nível de conhecimento cultural e o perfil do discente.

Isso leva a crer que, dependendo desses aspectos que o docente vai se deparar, é que ele pode em uma mesma disciplina ministrá-la de formas diferentes, porque assim poderá definir quais as melhores metodologias para atender ao objetivo de fazer com que o aluno apreenda o conteúdo proposto para aquela unidade.

Outro aspecto levantado nas falas dos sujeitos foi o conteúdo ministrado, que é adequado de acordo com a capacidade docente em avaliar qual a metodologia mais adequada a seu perfil como docente e aos aspectos relacionados às peculiaridades de cada disciplina.

A pesquisa identificou ainda nos discursos dos sujeitos que, quando o professor tem um perfil e postura de ensino mais inovador, quando ele encontra uma unidade curricular com conteúdos mais práticos, ele consegue utilizar e adotar uma metodologia mais dinâmica.

Assim, o fato de haver disciplinas com um viés mais prático permite ao docente que costuma adotar uma escolha metodológica mais ativa utilizar e destacar essas metodologias. Nesse sentido, esse docente que se sente mais à vontade com uma escolha metodológica mais inovadora também busca nas disciplinas que tenham uma base mais teórica propor metodologias de ensino mais ativa, fazendo com que o aluno participe do processo de construção do conhecimento.

Assim, Cunha (2012) aponta que levar em conta essas premissas é também refazer as concepções sobre o conhecimento e sobre a ação de ensinar e aprendê-lo.

Ideia corroborada por Nunes (2001), quando diz que a educação do professor deverá passar por uma nova concepção do processo ensino aprendizagem, com a recolocação do conhecimento na perspectiva histórico-social.

Nas falas dos respondentes são ressaltadas características que são levadas em conta no momento da escolha da metodologia a ser utilizada em sala, que surge por meio da percepção do docente a possibilidade de uma identificação 
de estratégias metodológicas que são fundamentais para o andamento do processo de ensino e aprendizagem. Perceber os aspectos relacionados à perspectiva histórico-social da turma, os conteúdos e os aspectos que influenciam os diferentes propósitos das disciplinas faz com que o docente tenha a possibilidade de proporcionar aos discentes e a eles próprios experiências que podem afetar no que diz respeito ao desenvolvimento e à maior participação entre as partes.

Percebe-se também que, apesar da maior parte dos docentes adotarem o pluralismo metodológico, há uma ênfase desses professores para a adoção de um pluralismo voltado mais para a metodologia tradicional, como é percebido em um segundo momento nos trechos das falas:

"Logicamente para cada disciplina a gente acaba utilizando algumas metodologias mais especificamente, em outras não, mas normalmente eu utilizo o formato de mais aulas expositivas tradicionais".

"A metodologia inicialmente é aquela clássica, a aula expositiva, utilizando o recurso audiovisual... O que eu faço, depende muito das disciplinas".

Os professores que utilizam essa escolha metodológica pluralista com ênfase em uma abordagem de ensino tradicional justificam a decisão ao fato de se depararem com um número elevado de alunos por turma, como também a existência de um perfil discente com realidades sociais distintas, além de estarem acostumados a metodologias de ensino mais tradicionais, adotadas no Ensino Médio. Nesse contexto são destacadas as falas:

"Eu tenho muitos alunos, são turmas muito grandes de 40, 50 pessoas. Não dá pra gente ficar inventando muito".

"Os alunos que acabaram de entrar na universidade e ainda estão muito acostumados com a metodologia do ensino médio e com a passividade do aluno, em que o aluno fica em seu lugar e o professor passa o conteúdo como se ele fosse o único transmissor de conteúdo e o aluno tivesse pouca participação no processo".

"(...) A realidade social, caracterizada por grande complexidade". 
Em relação às outras questões de pesquisa, a maior parte dos docentes relacionou dois fatores que impactam diretamente, tanto nas dificuldades quanto nos desafios, para implantar metodologias de ensino ativas no Curso de Turismo, os fatores: motivação e falta de compreensão do aluno em relacionar o conteúdo ou as atividades ministradas em sala de aula com situações da vida organizacional em que poderá vivenciar como turismólogo.

O desafio de motivar é demonstrado nas falas apresentadas no Quadro 1.

Quadro 1 - Desafio de motivar

\begin{tabular}{|c|c|}
\hline Sujeito & Fala \\
\hline P11 & $\begin{array}{c}\text { Se espera,... ao motivarmos, que eles se expressem, que eles dialoguem, que eles enfim, contribuam } \\
\text { na construção e no desenvolvimento daquelas competências e conhecimentos... dar ao aluno uma } \\
\text { motivação, fazer com que ele tenha mais vontade de participar e sentir-se desafiado. }\end{array}$ \\
\hline P04 & Problemas e desafios relacionados ao interesse do alunado pelo curso e/ou disciplina. \\
\hline P08 & $\begin{array}{c}\text { Os desafios, o principal é motivar, a gente vem discutindo entre os professores maneiras de } \\
\text { motivar esses alunos. }\end{array}$ \\
\hline P01 & $\begin{array}{c}\text { Eu sinto a necessidade de motivá-los, eu sinto que às vezes eu até acabo exagerando ao tentar } \\
\text { puxar e buscar o (vamos dar o máximo, para conseguir um bom rendimento). Acho que falta } \\
\text { muita motivação. }\end{array}$ \\
\hline
\end{tabular}

Fonte: Dados da pesquisa.

Enquanto o outro aspecto desse tópico é o desafio de fazer com que o discente perceba a importância do conteúdo trabalhado em sala de aula. Como se percebe nas falas do Quadro 2:

Quadro 2 - Percepção da importância do conteúdo trabalhado

\begin{tabular}{|c|c|}
\hline Sujeito & Fala \\
\hline P01 & O grande desafio é o aluno perceber a importância do conteúdo que está sendo transmitido. \\
\hline P12 & $\begin{array}{r}\text { Eles ainda não se sentem atores sociais, falta ter noção do grande horizonte de trabalho em } \\
\text { turismo que se tem. }\end{array}$ \\
\hline P14 & $\begin{array}{r}\text { A dificuldade seria fazê-los enxergar que aquela tarefa que eu trago para dentro de sala vai ser } \\
\text { algo que eles vão utilizar, é algo real e que eles vão vivenciar quando estiverem fora do curso e } \\
\text { estiverem realmente atuando no mercado. }\end{array}$ \\
\hline P20 & $\begin{array}{r}\text { Eles percebam que estão buscando aqui um conhecimento para o mercado de trabalho e } \\
\text { muitas vezes eles não entendem que estão buscando isso. }\end{array}$ \\
\hline
\end{tabular}

Fonte: Dados da pesquisa.

Talvez essas dificuldades e desafios estejam relacionados ao fato de os alunos serem ainda muito jovens e tomarem decisões de carreira muito cedo, ou ainda ao fato de escolherem o curso sem que essa tenha sido a sua primeira opção de escolha, ocasionando assim uma falta de interesse e de conhecimento em relação ao curso. Se o discente está em um curso que 
talvez não seja o que ele almeja ou que pretenda continuar, provavelmente não terá o mesmo nível de comprometimento e dedicação do que um aluno que fez uma escolha mais consciente.

Nesse contexto, os docentes se deparam ainda com outros desafios e dificuldades na aplicação das metodologias de ensino, que é conquistar um discente que possui certas carências de conhecimento, desconhece as áreas de atuação e nem sempre tem vocação para atuar no turismo, conforme apresentado no Quadro 3.

Quadro 3 - Dificuldades na aplicação das metodologias de ensino

\begin{tabular}{|c|c|}
\hline Sujeito & Fala \\
\hline P11 & $\begin{array}{l}\text { Nível baixo de leitura do aluno, nível baixo de cultura geral do aluno, nível baixo de } \\
\text { conhecimentos técnicos desse mesmo aluno e em alguns casos a não vocação do aluno para a } \\
\text { área, isso torna difícil a execução de qualquer metodologia, mas principalmente metodologias } \\
\text { de dialogo, porque, para se dialogar, você tem que ter conteúdo, então o aluno que não lê tem } \\
\text { dificuldade de participar ativamente. }\end{array}$ \\
\hline P06 & Eu também vejo que os alunos leem muito pouco, então a aula expositiva acaba que resolve mais. \\
\hline P08 & $\begin{array}{l}\text { A gente percebe uma dificuldade na área de construção mesmo de base, às vezes tem alunos } \\
\text { que tem dificuldade de leitura, dificuldade de escrita, e que algumas metodologias acabam } \\
\text { aflorando e a gente percebe essas limitações. }\end{array}$ \\
\hline P06 & O nível de leitura é baixo. Isso é um problema pra trabalhar. \\
\hline P29 & $\begin{array}{l}\text { Fazer com que os alunos leiam... que eles realmente adentrem nos livros... é fazer com que } \\
\text { os alunos enxerguem a importância da leitura, a importância de ter conteúdo... e ter uma } \\
\text { formação mais densa. }\end{array}$ \\
\hline P06 & $\begin{array}{l}\text { Olha, eu vejo que o pessoal de turismo tem muita dificuldade para aceitar teoria, ler, discutir. } \\
\text { Tem certa resistência para teoria. }\end{array}$ \\
\hline P09 & $\begin{array}{l}\text { Geralmente é perder o medo da leitu } \\
\text { semestre inteiro é uma batalha para vo }\end{array}$ \\
\hline P12 & $\begin{array}{c}\text { Acredito que seja a questão da leitura. Eles têm muita dificuldade e não acho que seja só } \\
\text { uma questão de geração, eles têm cada vez mais dificuldade em se concentrar e direcionar a } \\
\text { atenção para a leitura. }\end{array}$ \\
\hline P11 & $\begin{array}{c}\text { Nível baixo de leitura do aluno, nível baixo de cultura geral do aluno, nível baixo de } \\
\text { conhecimentos técnicos desse mesmo aluno e em alguns casos a não vocação do aluno para a } \\
\text { área, isso torna difícil a execução de qualquer metodologia. }\end{array}$ \\
\hline P14 & $\begin{array}{c}\text { Como a disciplina é muito focada no mercado, eles não querem ler. Fazê-los ler é um } \\
\text { grande problema. }\end{array}$ \\
\hline
\end{tabular}

Fonte: Dados da pesquisa.

A nova forma de organizar o processo de ensino, que altera a forma memorativa e passa ao desafio de realizar operações mentais, provoca desafios e o ato de pensar e não é algo simples e direto, é preciso ter disposição para pensar (Anastasiou e Alves, 2012).

E o pensar exige leitura, não uma leitura só por ler, a leitura surge no processo como o elo inicial entre docente, discente e conteúdo, não há só o repasse da 
informação. Quando se exige a leitura, retira-se o estudante de uma posição cômoda de receptor de informação e passa a exigir uma troca de informação, uma avaliação do que se entende, uma percepção de assuntos e mundos e como essa competência não é algo frequente na vida estudantil, a princípio, pode se tornar um pouco desafiante.

Outra reflexão que pode ser levantada é que o mundo da informação atualmente surge de forma bem visual como também de mensagens e textos curtos, em que conseguem passar ideias e visões centrais de variados assuntos de forma fácil e simplificada e como essa nova geração é proveniente dessa nova forma de ver o mundo, talvez a falta de estímulo da leitura em sua educação inicial possa ter provocado certa aversão ou dificuldade na leitura.

Os professores destacaram, ainda, dificuldades e desafios na sua atuação profissional como docente. Um dos aspectos citados foi a dificuldade de implementar no dia a dia uma metodologia mais ativa com os conceitos que devem ser trabalhados em sala, apesar de entenderem que os alunos, em alguns casos, valorizam essa postura, conforme Quadro 4.

Quadro 4 - Dificuldades e desafios na atuação profissional como docente

\begin{tabular}{|c|c|}
\hline Sujeito & Fala \\
\hline P10 & $\begin{array}{c}\text { Eu sinto que os alunos do curso de turismo têm esse perfil mais dinâmico... Mas eu enquanto } \\
\text { professora, sinto essa dificuldade de implementar no dia a dia... como eu falei, eu sinto essa } \\
\text { dificuldade de conseguir metodologias mais dinâmicas e que consigam trabalhar o conceito de } \\
\text { forma mais profunda e que traga essas reflexões. }\end{array}$ \\
\hline P20 & $\begin{array}{r}\text { Eu sinto essa dificuldade de não conseguir trabalhar teorias, conceitos, categorias e definições } \\
\text { de uma forma mais lúdica. }\end{array}$ \\
\hline P23 & $\begin{array}{c}\text { Em relação às metodologias mais tradicionais eu as adoto pela dificuldade que eu sinto em } \\
\text { inovar para passar aquele conteúdo que é necessário... e não consigo vislumbrar essa base } \\
\text { teórica da disciplina. }\end{array}$ \\
\hline
\end{tabular}

Fonte: Dados da pesquisa.

Mesmo sabendo que o aluno prefere um maior dinamismo em sala de aula, nos discursos dos docentes a palavra "dificuldade" surgiu em todos os comentários, demonstrando que os professores possuem uma preocupação, um receio e resistência em adotar uma postura metodológica mais ativa, principalmente quando ele percebe que o aluno tem dificuldade em ler e escrever, além de outras limitações, como também ele próprio, como professor, tem suas limitações em relação ao entendimento da nova proposta. 
Assim, ele se depara com uma série de dilemas: irei trabalhar com um sistema metodológico mais participativo, mesmo sabendo que caso seja adotado esse modelo, talvez ele não seja bem compreendido? Reduzirei a densidade teórica da minha antiga disciplina, em que tinha total domínio do conteúdo, com o uso da aula expositiva para adotar uma postura de ensino dinâmica e participativa que exigirá novas competências em que ainda não se está habituado? E os alunos, conseguirão aprender com essa nova metodologia, mesmo sem ter uma postura de autonomia e busca de conhecimento pela falta de hábito da leitura? Ou utiliza a metodologia tradicional, por perceber que apesar de não ser a mais adequada, talvez seja a mais apropriada para uma turma com esse perfil?

No momento que o docente sabe explicitar as suas próprias práticas e estabelece seu próprio desenvolvimento e processo de formação continuada, promove transformações que vão propiciar uma melhor utilização no uso de metodologias que a princípio não estava acostumado a utilizar. E assim, ter a possibilidade de dirigir e organizar situações de aprendizagem junto aos alunos.

Outro aspecto apontado como uma dificuldade dos docentes que poderia impactar na aplicação de metodologias ativas no ensino de turismo diz respeito à composição da maioria do quadro de docentes do curso pertencer a diferentes áreas de conhecimento, que encaminham professores para ministrarem disciplinas de Turismo, uma vez que o curso demanda profissionais das mais diversas áreas de formação.

Além disso, esses professores talvez não tenham tido a oportunidade de se conhecerem e de planejarem metodologias de ensino, integrando conhecimento com as outras disciplinas oferecidas por professores que ministram outra unidade curricular, ou até de conhecerem de perto o projeto pedagógico do curso e o perfil profissional exigido para a formação do turismólogo. Essa aproximação do docente com as competências exigidas pela formação e que são apresentadas no projeto pedagógico do curso são relevantes para a escolha de uma metodologia de ensino que permita o desenvolvimento dessas exigências profissionais. 
Desta forma, a metodologia de ensino aprendizagem deve acompanhar os objetivos pretendidos pela instituição e aprendizagem dos alunos. Se a instituição e o projeto pedagógico do curso preveem que seus alunos sejam proativos, torna-se necessário adotar metodologias que propiciem o desenvolvimento nos alunos dessa postura de autonomia, envolvendo-os em várias atividades que os faça refletir, discutir, agindo com comprometimento e dedicação, focando na resolução de problemas e avaliação dos impactos dos resultados de processos decisórios relacionados ao turismo.

Assim, na instituição pesquisada, esse distanciamento do docente com a realidade do curso ocorre, já que o docente está vinculado a um centro ou departamento acadêmico, mas que pode ser utilizado em cursos das mais diversas áreas de conhecimento, fazendo com que a sua carga horária seja distribuída em vários cursos. Ressalta-se que, apesar de o professor possuir o domínio de conhecimento da temática da disciplina, não necessariamente consegue adequar aquele conhecimento para as particularidades de formação profissional da área de turismo, como também não há um diálogo frequente nas relações entre a equipe de professores e a coordenação do curso. Essa comprovação pode ser identificada no Quadro 5:

Quadro 5- Relacionamento entre os diferentes departamentos

\begin{tabular}{|c|c|}
\hline Sujeito & Fala \\
\hline P19 & $\begin{array}{c}\text { Penso que troca de experiência entre cursos, entre departamentos, ou projetos de pesquisa ou } \\
\text { de extensão, que envolvesse alunos de outros departamentos...penso que poderia ser melhor } \\
\text { trabalhado, mas isso, é um pouco complicado, porque as vezes no próprio centro a gente não } \\
\text { dialoga muito com os outros cursos... Penso que isso seria interessante para agregar valor a } \\
\text { formação do aluno de turismo. }\end{array}$ \\
\hline P03 & $\begin{array}{r}\text { Percebo a necessidade de uma interdisciplinaridade maior, onde os professores do curso } \\
\text { poderiam ter um seminário de atualização onde poderia ser debatido não apenas as } \\
\text { metodologias, mas os conteúdos e a produção na área. }\end{array}$ \\
\hline
\end{tabular}

Fonte: Dados da pesquisa.

Essa carência na articulação do curso se refere tanto à aproximação entre as disciplinas quanto à relação com as demais áreas de conhecimento, que encaminham professores para o curso e que pertencem a outros departamentos da universidade.

O Curso de Turismo é multidisciplinar e devido a essa característica conta com a participação de docentes dos mais diversos centros de ensino, e sem que 
haja uma interação entre esses centros, provavelmente não ocorrerá também com o corpo docente. E nesse sentido, sem uma interação que proporcione um melhor entendimento do que se esperar do curso, perdem-se oportunidades em projetos de pesquisa e extensão que poderiam ser desenvolvidos em conjunto, como também a possibilidade do desenvolvimento de novas competências para o discente, que teria a oportunidade de ter uma nova visão de curso, uma visão sistêmica relacionada aos demais cursos que fazem parte da estrutura curricular da graduação de turismo.

Quando se fala em desafios e dificuldades, vários são os aspectos que podem ser associados. Aqui foram destacados os que para os docentes são os mais importantes e que podem dificultar o desenvolvimento, seja da disciplina de forma individual como também todo o curso.

Motivar e fazer com que o aluno tenha consciência de que o que é visto em sala pode e deve ser associado ao mercado de trabalho, ao mesmo tempo, os docentes também relatam que o ensino do turismo não está conseguindo acompanhar o desenvolvimento e os anseios do mercado de trabalho, seja pela burocracia da instituição ou pela necessidade de adaptação e atualização de conteúdos e ementas.

E o docente, consciente de seu papel e conhecedor de variadas metodologias, também tem dificuldade em utilizá-las quando em sua sala de aula encontra um aluno que tem dificuldade no quesito leitura, fator preponderante para o crescimento profissional, o que provoca certo ciclo vicioso.

O aluno com um perfil de pouca leitura e desmotivado, com algumas lacunas e carências de conhecimento, além disso, em alguns momentos não compreende a razão de ser de determinadas metodologias ou disciplinas, talvez pelo fato de ser muito jovem e talvez não ter escolhido o Curso de Turismo como uma primeira opção de escolha, o que acaba inibindo o docente na utilização de diversas práticas que possam levar o discente para uma realidade que possa associar a teoria vista em sala com o que acontece com o mercado de trabalho. Sem essa consciência e a busca dessa visão, o curso acaba por ser afastar das necessidades do mercado, o que provoca a desmotivação e o ciclo recomeça. 
O trabalho teve como objetivo discutir sobre as dificuldades e os desafios da aplicação de metodologias ativas no ensino de turismo em uma instituição pública de ensino superior. Os dados levantados apontaram para as seguintes conclusões:

- Em relação às metodologias adotadas na sua disciplina, a metodologia que mais se destaca junto aos docentes que atuam no Curso de Turismo da instituição compreende o pluralismo metodológico, combinando assim metodologias na sua unidade curricular, tanto metodologias ativas como tradicionais;

- Os docentes apontaram o conteúdo da disciplina e/ou o perfil da turma como razões e motivos que influenciaram na escolha do pluralismo metodológico;

- Em relação à escolha metodológica, os professores entendem que essa escolha será deles, entendendo valorizar, nessa decisão, os aspectos: econômicos, sociais, nível de conhecimento cultural e perfil do discente. Assim, dependendo desses aspectos que o docente vai se deparar, é que ele pode em uma mesma disciplina ministrá-la de formas diferentes;

- Outro aspecto levantado foi que, na percepção dos docentes, quando ele se depara com uma unidade curricular ou com conteúdos mais práticos, ele consegue utilizar e adotar uma metodologia mais dinâmica; por outro lado, quando ministra uma disciplina ou conteúdos que julga serem mais tradicionais, adota uma metodologia com esse perfil;

- Nas falas dos respondentes, identificaram-se, ainda, características que são levadas em conta no momento da escolha da metodologia a ser utilizada em sala, sendo os aspectos relacionados à perspectiva histórica e social da turma;

- Apesar de a maior parte dos docentes adotarem o pluralismo metodológico, há uma ênfase desses professores para a adoção de um pluralismo voltado mais para a metodologia tradicional, justificando a decisão ao fato de se depararem com um número elevado de alunos por turma, como também a existência de um perfil discente com realidades sociais distintas, além de estarem acostumados a metodologias de ensino mais tradicionais, adotadas no Ensino Médio. 
- O estudo concluiu ainda que as dificuldades e os desafios que mais se destacaram na percepção docente dizem respeito a motivar o aluno e a fazer com que ele perceba a contribuição proporcionada pela teoria apresentada em sala de aula na formação profissional. Ao mesmo tempo em que motivar foi evidenciado como uma dificuldade, também foi destacado como um desafio. Essa ocorrência também se repetiu com o dilema e o desafio da compreensão do discente.

- Ainda foi mencionada pelos docentes como um fator que compromete na aplicação das metodologias de ensino a dificuldade da leitura por parte de alguns discentes;

- Outra dificuldade dos docentes que poderia impactar na aplicação de metodologias ativas no ensino de turismo diz respeito à falta de oportunidade dos professores de se conhecerem e de planejarem metodologias de ensino, integrando conhecimento com as outras disciplinas oferecidas, pois o quadro de docentes do curso pertence a diferentes áreas de conhecimento, que encaminham professores para ministrarem disciplinas de Turismo, uma vez que o curso demanda profissionais das mais diversas áreas de formação. Além disso, esses professores talvez não tenham tido, ou até de conhecerem de perto o projeto pedagógico do curso e o perfil profissional exigido para a formação do turismólogo.

Os docentes provenientes de outros departamentos também destacaram como dificuldade a falta de diálogo entre os centros, os cursos e os docentes que atuam em vários cursos da instituição para contemplar os interesses e as exigências de desenvolvimento de competências e formação de cada curso em que atua.

\section{REFERÊNCIAS}

Anastasiou, L. G. C. \& Alves, L. P. (Orgs) (2012). Processos de ensinagem na universidade: pressupostos para as estratégias de trabalho em aula. Joinville: Univille.

Bhandari, Kalyan (2017). Teaching evaluation practices: An early career practitioner's reflections. Journal of Hospitality, Leisure, Sport \& Tourism Education, 20, 27-31. 
Bourdieu, P. (1996). Razões práticas: sobre a teoria da ação. Campinas: Papirus.

Capra, F. (2006). O ponto da mutação: a ciência, a sociedade e a cultura emergente. Cultrix: São Paulo.

Colom, A. J. (2006). Complejidad y teoría del caos en educación. In Rego, M. \& Tostado A. (Orgs). Avances en complejidad y educación: teoría y práctica. Barcelona: Octaedro.

Corrêa, Guilherme Torres, \& Ribeiro, Victoria Maria Brant. (2013). A formação pedagógica no ensino superior e o papel da pós-graduação stricto sensu. Educação e Pesquisa, 39(2), 319-334.

Costa, Gilvan Bernardo (2013). CCSA 40 anos: uma síntese histórica 1973-2013. Natal: UFRN.

Cunha, M. I. (2012). O bom professor e sua prática. Campinas: Papirus.

Daniel, Ana Dias, Costa, Rui Augusto, Pita, Mariana \& Costa, Carlos (2017). Tourism Education: What about entrepreneurial skills? Journal of Hospitality and Tourism Management, 30, 65-72.

Duarte, Rosália. (2002). Pesquisa qualitativa: reflexões sobre o trabalho de campo. Cadernos de Pesquisa, (115), 139-154.

Fonseca, G. F. \& Magalhães, R. C. B. P. Educação inclusiva e identidade do pedagogo: achados de pesquisa em uma escola na Cidade de Natal-Rio Grande do Norte-Brasil. Espacios, 37 (18), 2016.

Fiorentini, D. \& Melo, G. F. S. (1998). Saberes docentes: Um desafio para acadêmicos e práticos. In Geraldi, C. (org). Cartografias do trabalho docente: Professor (a)- pesquisador (a). Campinas: ALB.

Freire, P. (2014). Pedagogia da Autonomia: saberes necessários à prática educativa. São Paulo: Paz e Terra.

Lara, Luiz Fernando (2010). O ensino da administração nos cursos de turismo no Brasil e a formação do turismólogo. Revista Turismo Visão e Ação, 12(3), set-dez, 277-298.

Masetto, Marcos T. \& Gaeta, Cecilia (2015). Os desafios para a formação de professores do ensino superior. Rev. Triang., 8(2), jul./dez, 04-13.

Nunes, C. M. F. (2001). Saberes docentes e formação de professores: um breve panorama da pesquisa brasileira. Educação \& Sociedade, 22(74).

Perrenoud, P. (1993). Práticas pedagógicas, profissão docente e formação: perspectivas sociológicas. Lisbos: Dom Quixote.

Ponte, João Pedro (2006). Estudos de caso em educação matemática. Bolema, 25, 105-132. 
Santos A. C. (2001). Gestion del conocimiento: analisis y proyeccion de los recursos humanos. Cuba: CUJAE, 2001.

Silveira, Carlos Eduardo, Medaglia, Juliana \& Gândara, José Manoel Gonçalves (2012). Quatro décadas de ensino superior de turismo no Brasil: dificuldades na formação e consolidação do mercado de trabalho e a ascensão de uma área de estudo como efeito colateral. Revista Turismo Visão e Ação,14(1), jan-abr, 06-18.

Sogayar, Roberta Leme \& Rejowski, Mirian (2011). Ensino superior em turismo em busca de novos paradigmas educacionais: problemas, desafios e forças de pressão. Revista Turismo Visão e Ação, 13(3), set-dez, 282-298.

Strauss, A. L. \& Corbin, J. (2009). Pesquisa qualitativa: técnicas e procedimentos para o desenvolvimento. Porto Alegre: Artmed.

\section{CONTRIBUIÇÃO DOS AUTORES NA CONSTRUÇÃO DO ARTIGO}

SEIXAS: Coleta de dados e elaboração da versão inicial.

ARAÚJO: Elaboração da versão inicial e revisão final.

BRITO: Elaboração da versão inicial e revisão final.

FONSECA: Elaboração da versão inicial, revisão dos conteúdos de educação. 